\title{
研究简报
}

\section{关于多项式的不可分解 性}

\author{
谢庭藩裴定一 \\ （杭州大 学）（大庆油田研究院）
}

Oskar Perron ${ }^{[1]}$ 和 Leon Bernstein ${ }^{[2]}$ 指出, 大部分判别整系数多项式在有理数域不可分 解 (本文所说不可分解均指在有理数域)的方 法, 都是利用整除性. 他们研究了用系数间 的不等式来刻划不可分解的方法。但他们用 的条件都较强，证明也复杂. 在见到这些资 料之前, 我们已经得出本文所用的方法, 这方 法既简单, 又可得到更好的结果.

定理 1 整系数多项式

$$
f(x)=a_{0} x^{n}+a_{1} x^{n-1}+\cdots+a_{n-1} x+a_{n}, \text { (1) }
$$

其系数若适合

$$
\begin{aligned}
& \left|a_{n-1}\right|>\left|a_{0} a_{n}^{n-1}\right|+\left|a_{1} a_{n}^{n-2}\right| \\
& \quad+\cdots+\left|a_{n-2} a_{n}\right|+1,\left|a_{n}\right| \neq 0, \text { (2) }
\end{aligned}
$$

则 $f(x)$ 不可分解.

证 在圆周 $|x|=\left|a_{n}\right|$ 上, 因为

$$
\begin{gathered}
\left|a_{n-1} a_{n}\right|>\left|a_{0} a_{n}^{n}\right|+\left|a_{1} a_{n}^{n-1}\right| \\
\quad+\cdots+\left|a_{n-2} a_{n}^{2}\right|+\left|a_{n}\right|,
\end{gathered}
$$

由 Rouche 定理, 可知在圆 $|x|<\left|a_{n}\right|$ 内 $f(x)$ 只有一个根 9 .

如果 $f(x)$ 可以分解, 则有 $f(x)=g(x)$ $\cdot h(x), g(x)$ 和 $h(x)$ 都为整系数多项式. 若 $g(\vartheta)=0$ (否则 $h(\vartheta)=0$ ), 则 $h(x)$ 的根的 模都 $>\left|a_{n}\right|$, 设 $h(x)$ 的次数为 $m$, 则

$$
\begin{aligned}
\left|a_{n}\right| & =|f(0)|=|g(0) h(0)| \\
& \geqslant|h(0)|>\left|a_{n}\right|^{m},
\end{aligned}
$$

不可能,所以 $f(x)$ 不可分解.

例 $1 x^{2}+b x+c(b, c$ 为整数, $c \neq 0)$. 如有

$$
|b|>|c|+1,
$$

则不可分解。这一结论也可以直接推出, 若
存在二个整数根 $\lambda_{1}, \lambda_{2}$, 则

$$
\begin{aligned}
|c|+1 & =\left|\lambda_{1} \lambda_{2}\right|+1 \geqslant\left|\lambda_{1}\right|+\left|\lambda_{2}\right| \\
& \geqslant\left|\lambda_{1}+\lambda_{2}\right|=|b|,
\end{aligned}
$$

即得所证. 易见, 仅当 $\lambda_{1}, \lambda_{2}$ 至少有一个为 \pm 1 且 $\lambda_{1} \lambda_{2}>0$ 时,上式等号成立.

例 2 当 $|L|>2$ ( $L$ 为整数) 时, $x^{n}+$ $L x \pm 1$ 不可分解.

取 $\left|a_{n}\right|=1, a_{1}=a_{2}=\cdots=a_{n-2}=0$, $a_{n-1}=L$, （2）式当然成立.

定理 $2 f(x)=x^{n}-x^{n-1}-x^{n-1}-\cdots$ $-x-1$ 不可分解.

证 易见

$$
(x-1) f(x)=x^{n+1}-2 x^{n}+1,
$$

任取正数 $\varepsilon\left(\frac{1}{2}>\varepsilon>0\right)$, 在圆周 $|x|=1+\varepsilon$ 上，

$$
\begin{aligned}
& \left|2 x^{n}\right|=2(1+\varepsilon)^{n}, \\
& \left|x^{n+1}+1\right| \leqslant 1+(1+\varepsilon)^{n+1},
\end{aligned}
$$

而

$$
\begin{gathered}
2(1+\varepsilon)^{n}-(1+\varepsilon)^{n+1}-1 \\
=(1+\varepsilon)^{n}(1-\varepsilon)-1 \\
>(1+n \varepsilon)(1-\varepsilon)-1 \\
=\varepsilon(n-1-n \varepsilon)>0,
\end{gathered}
$$

由 Rouche 定理及 $\varepsilon$ 的任意性, 可知 $x^{n+1}-$ $2 x^{n}+1$ 在圆 $|x| \leqslant 1$ 上有 $n$ 个根, 而当 $|x|=1$ 时仅有一个根 $x=1$, 所以 $f(x)$ 在圆 $|x|<1$ 内有 $n-1$ 个根, 只有一个根 9 在单位圆外. 若 $f(x)$ 可分解, 则有 $f(x)=g(x) h(x), g(x)$ 和 $h(x)$ 是首项系数为 1 的整系数多项式, 显

本文 1973 年 12 月 8 日收到。 
然有

$$
|g(0)|=|h(0)|=|f(0)|=1,
$$

若 $g(\vartheta)=0$ (否则 $h(\vartheta)=0$ ), 则 $h(x)$ 所有 根的模都 $<1$, 这与 $|h(0)|=1$ 矛盾, 故 $f(x)$ 不可分解.

Perron 在资料 [1] 中的结果是定理 1 的 显然推论.

定理 3 (Perron) 多项式

$$
f(x)=x^{n}-a_{1} x^{n-1}-a_{2} x^{n-2}
$$$$
-\cdots-a_{n-1} x-1 \text {, }
$$

$a_{i}(i=1,2, \cdots, n-1)$ 为非负整数, 且

$a_{n-1}>n-1+a_{1}+a_{2}+\cdots+a_{n-2}$,

则 $f(x)$ 不可分解.

证 当 $n=2, a_{1}=1,2$ 时,直接验算可 知 $f(x)$ 不可分解. 当 $n=2, a_{1}>2$ 及 $n \geqslant 3$ 时, 结论由定理 1 直接推出.

Bernstein 在资料 [2] 中的结果也是定理 1 的显然推论:

定理 4 (Bernstein) 整系数多项式

$$
\begin{aligned}
f(x)= & x^{n}+a_{1} x^{n-1}+a_{2} x^{n-2} \\
& +\cdots+a_{n-1} x+a_{n},
\end{aligned}
$$

当系数适合

$$
\begin{aligned}
& \left|a_{n-1}\right| \geqslant 2\left|a_{n}\right|^{n+1}\left(1+\left|a_{1}\right|\right. \\
& \left.\quad+\cdots+\left|a_{n-2}\right|\right), \quad\left|a_{n}\right| \geqslant 2
\end{aligned}
$$

时, $f(x)$ 不可分解.

证 由于

$$
\begin{gathered}
2\left|a_{n}\right|^{n+1}\left|a_{i}\right|>\left|a_{i} a_{n}^{n-i-1}\right|, \\
(i=1,2, \cdots, n-2)
\end{gathered}
$$

及

$$
2\left|a_{n}\right|^{n+1}>\left|a_{n}\right|^{n-1}+1,
$$

由定理 1 直接推出结论.

附记 1 定理 1 的证明中, 如果在圆周 $|x|=\left|a_{n}\right|$ 上, $f(x)$ 无根, 则条件 (2)的“>” 可以改为“””。

附记 2 多项式 $x^{n} \pm 2 x \pm 1$, 除以下一 些情况外都不可分解:

$$
\begin{aligned}
& x^{2 m}+2 x+1, \\
& x^{n}-2 x+1, \\
& x^{2 m+1}-2 x-1 .
\end{aligned}
$$

附记 $3 x^{6 m+5}+x-1$ 可以被 $x^{2}-x+1$ 整除, 资料 [2] 中得出了 $x^{n}+x-1$ 都不可 分解的错误结论.

附记 4 我们证明了 $x^{n}+x-1$ 在单位圆 内有 $2\left[\frac{n+1}{6}\right]+1$ 个根, 当且仅当 $n=6 m+5$ 时, 在单位圆周上有二个根。 $x^{n}-x+1$ 在 单位圆内有 $2\left(\left[\frac{n-2}{6}\right]+1\right)$ 个根, 当且仅当 $n=6 m+2$ 时, 在单位圆周上有二个根.

\section{参考 资 料}

[1] Perron, O., Math. Ann., 64 (1907), 1.

[2] Leon Bernstein, Lect. Nat. in Math., 1971, 207. 